\title{
Estimation of genetic variability and selection response for clutch length in dwarf brown-egg layers carrying or not the naked neck gene
}

\author{
Chih-Feng $\mathrm{CHEN}^{\mathrm{a}, \mathrm{b}}$, Michèle Tixier-BoICHARD ${ }^{\mathrm{a} *}$ \\ ${ }^{a}$ Laboratoire de génétique factorielle, Département de génétique animale, \\ Institut national de la recherche agronomique, 78352 Jouy-en-Josas Cedex, France \\ b Department of Animal Science, National Chung-Hsing University, \\ Taichung, Taiwan
}

(Received 13 May 2002; accepted 12 August 2002)

\begin{abstract}
In order to investigate the possibility of using the dwarf gene for egg production, two dwarf brown-egg laying lines were selected for 16 generations on average clutch length; one line (L1) was normally feathered and the other (L2) was homozygous for the naked neck gene $N A$. A control line from the same base population, dwarf and segregating for the $N A$ gene, was maintained during the selection experiment under random mating. The average clutch length was normalized using a Box-Cox transformation. Genetic variability and selection response were estimated either with the mixed model methodology, or with the classical methods for calculating genetic gain, as the deviation from the control line, and the realized heritability, as the ratio of the selection response on cumulative selection differentials. Heritability of average clutch length was estimated to be $0.42 \pm 0.02$, with a multiple trait animal model, whereas the estimates of the realized heritability were lower, being 0.28 and 0.22 in lines L1 and L2, respectively. REML estimates of heritability were found to decline with generations of selection, suggesting a departure from the infinitesimal model, either because a limited number of genes was involved, or their frequencies were changed. The yearly genetic gains in average clutch length, after normalization, were estimated to be $0.37 \pm 0.02$ and $0.33 \pm 0.04$ with the classical methods, $0.46 \pm 0.02$ and $0.43 \pm 0.01$ with animal model methodology, for lines L1 and L2 respectively, which represented about $30 \%$ of the genetic standard deviation on the transformed scale. Selection response appeared to be faster in line L2, homozygous for the NA gene, but the final cumulated selection response for clutch length was not different between the L1 and L2 lines at generation 16.
\end{abstract}

dwarf chicken / naked neck gene / clutch length / genetic variability / selection response

\footnotetext{
* Correspondence and reprints
}

E-mail: boichard@jouy.inra.fr 


\section{INTRODUCTION}

The sex-linked dwarf gene, $D W$, has been described for many years [19] and is known to improve food efficiency and egg production in dam lines used for broiler production, as reviewed by Mérat [24]. But in egg-laying strains, the $D W$ gene has been shown to decrease egg production [6], and more particularly clutch length [1]. The clutch length is the number of eggs laid on consecutive days, which is one of the important components of the total number of eggs laid along a production cycle. Clutch length is inversely related to the interval between ovipositions, a trait that has been shown to be highly heritable [21,23, 45 ] and to be increased by about two hours by the $D W$ gene [43]. Consequently, selection for clutch length can be proposed as a specific approach for improving egg production of dwarf layers. In previous studies, clutch length has been shown to be moderately to highly heritable, with a high genetic correlation with egg number $[4,22,39]$. Furthermore, the association of the naked neck gene, $N A$, with the $D W$ gene, was previously found to have a favorable effect on egg weight and food efficiency [10]. Thus, a selection experiment was initiated in 1985, with the aim to improve clutch length in two lines of dwarf brown-egg layers, differing by their genotype for the $N A$ gene. In addition to the investigation of the genetic variability of clutch length in dwarf layers, this experiment also made it possible to examine the effect of the combination of two major genes, $D W$ and $N A$, on selection response.

The aim of the present study was to estimate heritability and direct selection response for average clutch length, after 16 generations of selection of dwarf brown-egg layers. The mixed model methodology was chosen because of its theoretical advantages for the estimation of genetic parameters in selected populations $[5,7,27-30,35,37,41]$. The estimates were compared to the results obtained with the classical methods of calculating the deviation from the control line, and estimating the realized heritability as the ratio of selection response to selection differentials [18].

\section{MATERIALS AND METHODS}

\subsection{Animals and housing}

The selection experiment in one direction has been conducted at Inra in Jouy-en-Josas since 1985, starting from a sex-linked dwarf base population (= generation 0), with 99 dams and 23 sires hatched in 1983. This population originated in 1982 from a cross between light and heavy dwarf lines, where the NA gene had been introduced in 1981. From the first generation, birds were separated, according to their genotype for the $N A$ gene, into three lines: two selected lines, and one control line. The L1 selected line was normally feathered, homozygous for the non-naked neck allele $\left(N A^{*} N\right)$, the L2 line 
was homozygous for the naked neck allele $\left(N A^{*} N A\right)$, and control line $\mathrm{C}$ was segregating for the three possible genotypes at the $N A$ locus. Because the base population exhibited a large variability and a high mean value for body weight, it appeared necessary to decrease body weight in lines L1 and L2. The females of the first two generations were selected on an index incorporating body weight, with a negative coefficient, egg weight and average clutch length, with positive coefficients, determined according to the expected genetic gains [42], and males were selected on individual body weight within each sire family. The average clutch length was calculated as the arithmetic mean of all clutches recorded, from the first egg until 42 weeks of age. From generation 2 on, selection was done solely on average clutch length. The females were selected on a within-sire basis, combining the individual value and the full-sib mean, assuming heritability value of 0.4 in both lines. Selection of males combined the within-sire full-sister mean and the deviation of the sire family mean from the general mean. The lines were reproduced with a 1-year generation interval. For each selected line, on average, 10 sires were selected each year out of 59 candidates, and 49 dams were selected out of 169 candidates until generation 16. For the control line, on average, 11 sires out of 46 males and 55 dams out of 159 females per generation were randomly selected, as far as performance was concerned, but the genotype at the $N A$ locus was taken into account so as to maintain a $50 \%$ frequency of the mutant $N A^{*} N A$ allele. After pooling the three lines, the data set included a total of 10595 birds consisting of 2616 male and 7979 female chickens. They were produced from 518 sires and 2609 dams. The performances of the 122 founder animals were not included.

Each year, the chicks of the three lines were hatched in 1 to 3 batches, 2 or 3 weeks apart, and were reared on the floor with a $10 \mathrm{~L} / 14 \mathrm{D}$ cycle. The sexes were separated and the lines were intermingled. They were vaccinated against the major poultry infectious diseases. Between 16 and 17 weeks of age, the pullets were moved into individual cages with a 3-tier system. The light cycle in the laying house was set to $16 \mathrm{~L} / 8 \mathrm{D}$ from the day of housing on. The layer mash containing $2600 \mathrm{kcal} \cdot \mathrm{kg}^{-1}$ and $15.5 \%$ crude protein was distributed $a d$ libitum. Ambient temperature was held constant at $23^{\circ} \mathrm{C}$, in order to avoid an interaction between the lines and the environment that could be due to the $N A * N A$ allele in the case of fluctuating temperatures. Egg production was recorded daily for each hen, including the date of lay and the status for each egg (normal, broken, soft-shelled, double-yolked).

\subsection{Statistical analysis}

\subsubsection{Data distribution and transformation}

The data of average clutch length was checked for skewness and kurtosis with the UNIVARIATE procedure of $\mathrm{SAS}^{\circledR}$ [33]. In order to satisfy the classical 
hypothesis for describing traits with a polygenic inheritance via a linear model with a normal error, a power transformation was used [11]. The transformation form is as follows:

$$
\begin{aligned}
g_{t}(x) & =\frac{x^{t}-1}{t \times \dot{y}^{(t-1)}} & \text { if } t \neq 0 \\
& =\log (x) & \text { if } t=0
\end{aligned}
$$

where $\dot{y}$ is the geometric mean of the $y$ 's. This transformation relies on a single parameter $t$, empirically chosen to simultaneously fulfill several desirable criteria, as proposed by Ibe and Hill [20] and Besbes et al. [8].

\subsubsection{Phenotypic trends, line effects and the effect of the genotype at the NA locus}

The phenotypic variability and yearly trend of clutch length were compared among the three lines. The contrast between the lines was estimated for each year with Model I, whereas the effect of the genotype at the NA locus was estimated in the control line only with Model II, using the General Linear Models (GLM) procedure [32]:

$$
\begin{array}{ll}
\text { Model I: } & Y_{i j k l}=\mu+(\operatorname{year} \times h)_{i j}+(\operatorname{year} \times l)_{i k}+e_{i j k l} \\
\text { Model II: } & Y_{i j k l}=\mu+(\operatorname{year} \times h)_{i j}+G_{k}+e_{i j k l}
\end{array}
$$

where $Y_{i j k l}=$ the individual observation for clutch length, $\mu=$ the overall mean, $(\text { year } \times h)_{i j}=$ the fixed effect of the $j$ th hatch within the $i$ th year, $(\text { year } \times L)_{i k}=$ the fixed effect of the $k$ th line within the $i$ th year, $G_{k}=$ the fixed effect of the genotype at the NA locus within the control line, and $e_{i j k l}=$ the random error.

Only generations 6,8 , and 10 to 16 , of the control line were considered for model II, because the other generations exhibited either very few birds, or no bird, of each homozygous genotype at the NA locus.

\subsubsection{Coefficient of inbreeding}

In the first generation, the coefficient of inbreeding was assumed to be 0 , then individual inbreeding coefficients were computed by using the PEDIG package [9]. The program used the method described by Meuwissen and Luo [26], which was a modification of the method of Quaas [31].

\subsubsection{Estimated heritability of clutch length}

Variance and covariance components were estimated using the derivativefree multiple trait restricted maximum likelihood (REML) procedure with the 
VCE package of Groeneveld [16]. The three linear models considered in this study were (A) an animal model, (B) an animal model with a fixed effect for the genotype at the $N A$ locus, $(\mathrm{C})$ an animal model with a random permanent maternal environmental effect, and written as:

$$
\begin{array}{lrl}
\text { Model A: } & Y_{i j l}=\mu+(\text { year } \times h)_{i j}+a_{l}+e_{i j l} \\
\text { Model B: } & Y_{i j k l}=\mu+(\text { year } \times h)_{i j}+G_{k}+a_{l}+e_{i j k l} \\
\text { Model C: } & Y_{i j k l}=\mu+(\text { year } \times h)_{i j}+d_{i j k}+a_{l}+e_{i j k l}
\end{array}
$$

The notations for fixed effects were the same as in 2.2.2, with the addition of $a_{l}=$ the random animal effect ( $l=1$ to $\mathrm{m}, \mathrm{m}=$ the total number of records), $d_{i j k}$ a random effect common to all the progeny of dam $k$, and $e_{i j l}=$ the random error. The expectation and variance of the vector of performance, $y$, were distributed as follows, in a matrix notation:

$$
E\left[\begin{array}{l}
y \\
a \\
d \\
e
\end{array}\right]=\left[\begin{array}{c}
X \beta \\
0 \\
0 \\
0
\end{array}\right] \text { and } V\left[\begin{array}{l}
a \\
d \\
e
\end{array}\right]=\left[\begin{array}{ccc}
A \otimes G & 0 & 0 \\
0 & I_{N d} \otimes D & 0 \\
0 & 0 & \oplus_{l=1}^{m} R_{l}
\end{array}\right],
$$

where $y$ is the observed performance, $a$ is the individual additive genetic value, $d$ is the random permanent maternal environmental effect (Model C), $e$ is the residual, $\beta$ is either the vector of the year-hatch fixed effect (Model A, C) or is the vector of the year-hatch and genotype ( $N A$ gene) fixed effects (Model B); and $X$ its incidence matrix, $A$ is the numerator relationship matrix, $G$ is the variance-covariance matrix for the animal additive genetic effect, $I_{N d}$ is the identity matrix of dimension $N d$ (number of dams), $D$ is the variance-covariance matrix for the maternal environmental effect $d$ (Model C), $R_{l}$ is the residual variance-covariance matrix for the animal $l$. The direct product and direct sum of matrices are indicated by $\otimes$ and $\oplus$, respectively.

In order to take into account the effect of selection done on other traits at the beginning of this selection experiment, the four traits, clutch length, egg number, adult body weight and egg weight at 29 weeks were involved simultaneously in each analysis.

All the data were analyzed with model A, B and C to estimate genetic parameters in the base population. Moreover, we also analyzed each line as a separate data set, using Model A in the two selected lines (no NA genotype effect), and using Model B in the control line (with the NA genotype effect).

The stability of the heritability estimates was analyzed by increasing the number of generations successively taken into account in nine different subsets of the whole data set. Pedigree information back to generation 0 was included in the analysis to connect the three lines. The consequence of omitting performance data from earlier generations was investigated by analyzing three 
different subsets of data, namely generations G5-G8, G9-G12 and G13-G16, with the same model as previously described for the three lines, including pedigree information back to generation 0 .

In order to monitor the change in genetic variance along selection, another group of data sets was defined by excluding the data successively from generation 0 until generation 12 by 4 generations, ignoring back pedigree information. Model A was applied to the "descending" analysis of the two selected lines. Model B was applied to the analysis of the control line.

\subsubsection{Genetic gain}

Method I. Least Squares Methodology: The selection response in each line was estimated by the deviation from the control line, taking into account the initial difference at generation 1 . The cumulated selection response (CSR) at generation $n$ was calculated by:

$$
\mathrm{CSR}=\left(S_{n}-C_{n}\right)-\left(S_{1}-C_{1}\right)
$$

where $S_{n}$ and $C_{n}$ were least square means of Model I for average clutch length (transformed value) at generation $n$ in the selection line and control line, respectively.

Method II. Individual Animal Model: Estimated breeding values (EBV) were estimated by the best linear unbiased prediction (BLUP) using a mixed linear model, to evaluate genetic gain using the PEST package [17]. For this evaluation, variance components obtained from the REML analysis done with model $\mathrm{A}$ on the entire data set were used. Estimated breeding values were averaged per line and generation. Concomitantly, the individual inbreeding coefficient was used as a covariable, with the following model:

$$
\text { Model D: } \quad Y_{i j k l}=\mu+b I+(\operatorname{year} \times h)_{i j}+G_{k}+a_{l}+e_{i j k l}
$$

where $Y_{i j k l}=$ individual observation, $\mu=$ the overall mean, $b=$ the regression coefficient, $I=$ the individual inbreeding coefficient, $(\text { year } \times h)_{i j}=$ the fixed effect of the $j$ th hatch within the $i$ th year, $G_{k}=$ the fixed effect of the genotype at the NA locus, $a_{l}=$ the random animal effect and $e_{i j k l}=$ the random error.

\subsubsection{Realized heritability}

To enable the calculation of realized heritability, the actual selection differential for dams was calculated, at each generation, by the within-line difference between the average clutch length (transformed value) of selected birds, weighted by the number of dam's progeny, and the mean average clutch length (transformed value) of the population. For sires, without individual phenotypic observations, the selection differential was approximated by the 
difference between the mean record (transformed value) of full-sisters of each sire, weighted by the number of the sire's progeny, and the generation mean (transformed value). The cumulated selection differential (CSD), on the transformed scale, was then calculated as:

$$
\mathrm{CSD}=\sum_{n=1}^{16}\left(\frac{S D s_{n} \times i s_{n}+S D d_{n} \times i d_{n}}{i s_{n}+i d_{n}}\right)
$$

where $S D s_{n}$ and $S D d_{n}$ are the weighted selection differentials of sires and dams in generation $n, i s_{n}$ and $i d_{n}$ are the selection intensity of the sires and dams in generation $n$.

\section{RESULTS}

\subsection{Data distribution and transformation}

Figure 1 shows the data distribution of average clutch length before and after transformation. The average clutch length was modified by a Box-Cox power transformation to reduce non-normality and curvilinearity of heritability. The transformation parameter $(\mathrm{t})$ was -0.247 , and the skewness and kurtosis after transformation were 0.228 and -0.014 respectively.

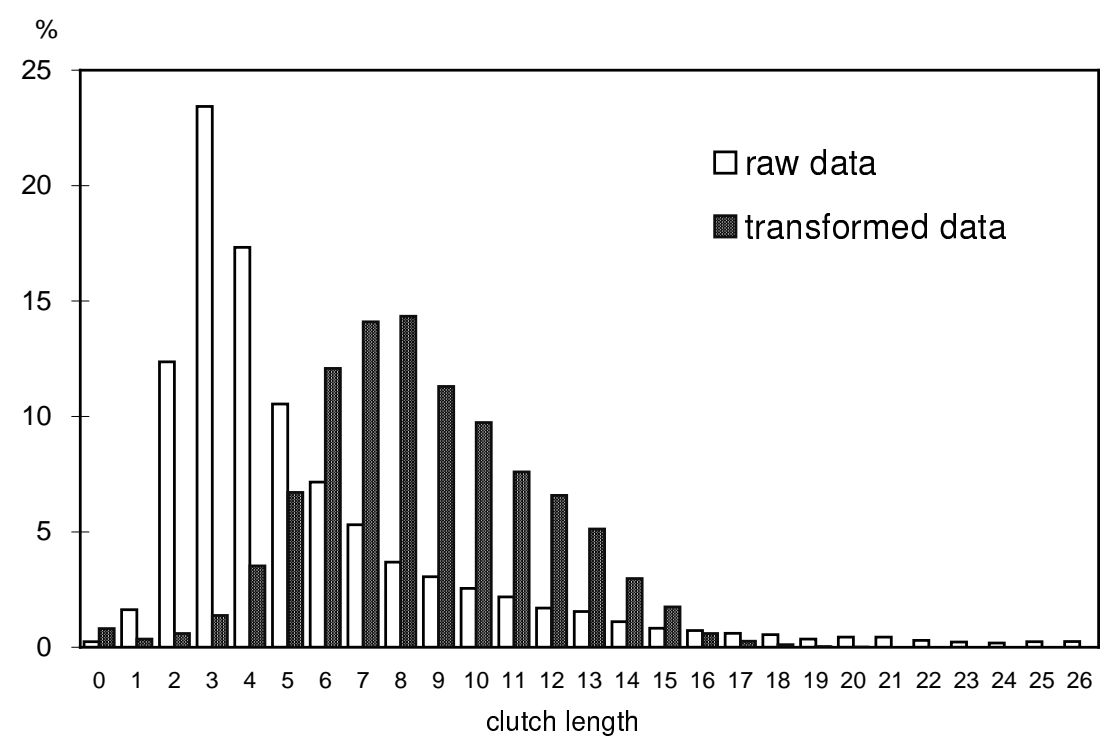

Figure 1. The distribution of average clutch length before/after the Box-Cox transformation. 
Table I. Number of recorded hens per generation in each genotype (normal = $N A^{*} N / N A^{*} N$, heterozygous $=N A^{*} N / N A^{*} N A$, naked neck $\left.=N A^{*} N A / N A^{*} N A\right)$.

\begin{tabular}{|c|c|c|c|c|c|c|}
\hline \multirow[t]{2}{*}{ Generations } & \multicolumn{3}{|c|}{ Control line } & \multirow{2}{*}{$\begin{array}{c}\text { L1 } \\
\text { (normal) }\end{array}$} & \multirow{2}{*}{$\begin{array}{c}\mathrm{L} 2 \\
\text { (naked neck) }\end{array}$} & \multirow[t]{2}{*}{ Total } \\
\hline & \multicolumn{3}{|c|}{$\begin{array}{r}\text { normal heterozygous naked } \\
\text { neck }\end{array}$} & & & \\
\hline G0 & & Male $=23$ & Female & (heterozygous) & & 122 \\
\hline G1 & - & 163 & - & 136 & 151 & 450 \\
\hline G2 & 16 & 136 & 19 & 157 & 161 & 489 \\
\hline G3 & 18 & 145 & 15 & 187 & 179 & 544 \\
\hline G4 & - & 174 & - & 189 & 179 & 542 \\
\hline G5 & - & 136 & - & 215 & 195 & 546 \\
\hline G6 & 58 & 63 & 67 & 185 & 179 & 552 \\
\hline G7 & 2 & 135 & 7 & 140 & 171 & 455 \\
\hline G8 & 30 & 50 & 22 & 109 & 149 & 360 \\
\hline G9 & 1 & 86 & - & 176 & 214 & 477 \\
\hline G10 & 31 & 67 & 35 & 171 & 156 & 460 \\
\hline G11 & 67 & 67 & 67 & 181 & 176 & 558 \\
\hline G12 & 49 & 92 & 35 & 160 & 162 & 498 \\
\hline G13 & 49 & 73 & 59 & 177 & 194 & 552 \\
\hline G14 & 47 & 79 & 45 & 200 & 191 & 562 \\
\hline G15 & 48 & 73 & 59 & 171 & 203 & 554 \\
\hline G16 & 53 & 64 & 54 & 102 & 107 & 380 \\
\hline
\end{tabular}

\subsection{Phenotypic trends, line effects, and effect of the $N A$ gene}

The number of hens with a record in each genotype per generation is presented in Table I for the 16 generations. Figure 2 shows the yearly phenotypic means in each line for average clutch length. The normally feathered line (L1) and the naked neck line (L2) differed significantly from the control line (C) starting at G5 and G4, respectively. Between the two selected lines, the mean of line L2 was significantly higher than the mean of line L1 beginning at G5 and until G13, but in the last three generations, lines L1 and L2 means did not differ significantly any more. In G12, an acute failure in water distribution affected the mean performance much more severely for line L2 than for line L1, and more severely for both selected lines than for the control line. The selection response was maintained, however, in G13, but the differences between lines L1 and L2 disappeared.

Within the control line, the least squares means for average clutch length was estimated to be $3.09,3.28$ and 3.34 for $N A^{*} N / N A^{*} N, N A^{*} N A / N A^{*} N$ and 


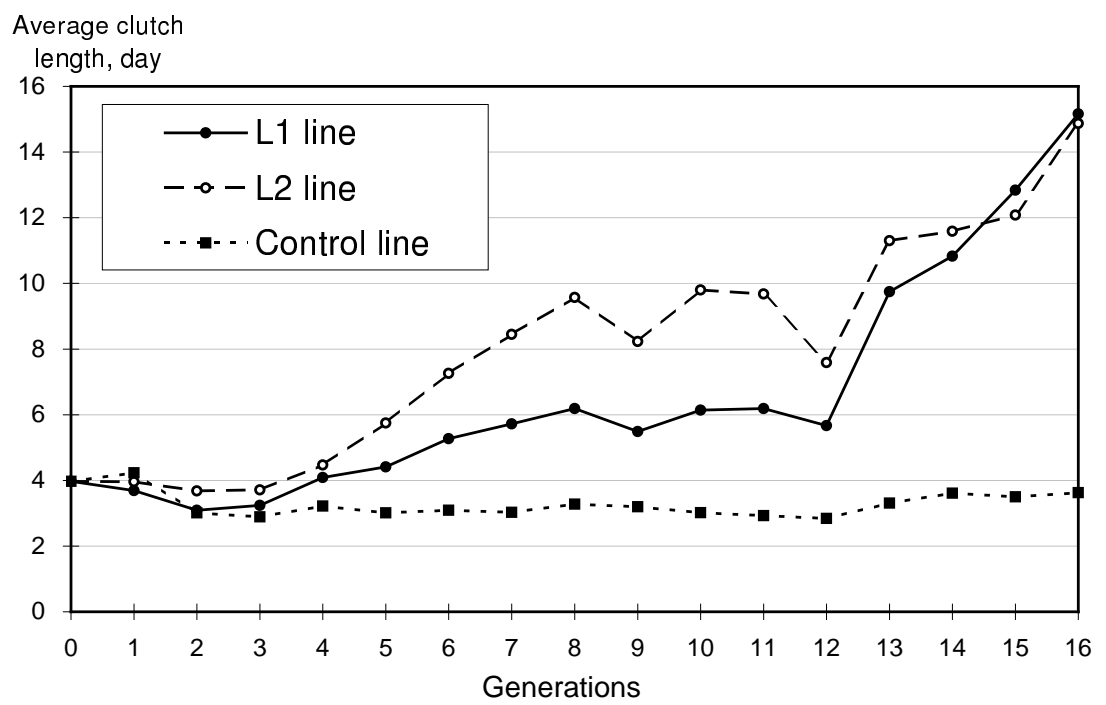

Figure 2. The phenotypic means in each line per generation for average clutch length. L1 line: selected and normally feathered; L2 line: selected line and naked neck line; control line: unselected and segregating for the naked neck gene.

$N A * N A / N A * N A$ genotypes, respectively. The normally feathered genotype showed a significantly shorter clutch length than either the heterozygous or the homozygous carrier of the naked neck mutation.

\subsection{Inbreeding level}

After 16 generations, the cumulated inbreeding level was the lowest in the control (C) (11.1\%), and showed very similar values in the normally feathered line (L1) and the naked neck line (L2) with $18.0 \%$ and $18.4 \%$, respectively. The average increment of the percent inbreeding coefficient per generation was $0.74 \%, 1.20 \%$ and $1.23 \%$ in line C, line L1 and line L2, respectively. A 10\% increase of inbreeding reduced the clutch length on the transformed scale by $1.16(\mathrm{~L} 1), 1.19$ (L2) and $0.29(\mathrm{C})$, according to the result of model D where the inbreeding coefficient was included as a covariable.

\subsection{The estimated heritability of clutch length}

The heritability of the average clutch length was estimated to be $0.42 \pm 0.02$ with a multiple trait animal model using the data on all the lines over 16 generations. The heritabilities estimated separately for each line were $0.41 \pm$ $0.03,0.36 \pm 0.03$ and $0.58 \pm 0.02$ in the normally feathered line (L1), the naked neck line (L2) and control line (C) respectively. When the analysis was run on an increasing number of generations, starting from G0, the estimated 
Table II. Estimated heritabilities of average clutch length according to three models with increasing numbers of generations.

\begin{tabular}{lcccccccc}
\hline Generation & \multicolumn{3}{c}{ Model A } & & \multicolumn{3}{c}{ Model C } & \multirow{2}{*}{ No. records } \\
\cline { 2 - 3 } \cline { 7 - 8 } & $h^{2}$ & SE & $\sigma_{G}^{2}$ & & $h^{2}$ & SE & $\sigma_{G}^{2}$ & \\
\hline G0-G1 & 0.510 & 0.065 & 2.042 & & 0.523 & 0.096 & 2.053 & 450 \\
G0-G2 & 0.517 & 0.030 & 2.037 & & 0.652 & 0.054 & 2.876 & 939 \\
G0-G4 & 0.555 & 0.024 & 2.248 & & 0.498 & 0.048 & 2.007 & 2025 \\
G0-G6 & 0.573 & 0.023 & 2.481 & & 0.484 & 0.040 & 1.990 & 3123 \\
G0-G8 & 0.541 & 0.020 & 2.529 & & 0.390 & 0.032 & 1.660 & 3938 \\
G0-G10 & 0.519 & 0.021 & 2.467 & & 0.403 & 0.029 & 1.772 & 4875 \\
G0-G12 & 0.481 & 0.014 & 2.397 & & 0.370 & 0.021 & 1.667 & 5931 \\
G0-G14 & 0.457 & 0.018 & 2.361 & & 0.324 & 0.029 & 1.494 & 7045 \\
G0-G16 & 0.421 & 0.018 & 2.206 & & 0.307 & 0.028 & 1.456 & 7979 \\
\hline
\end{tabular}

Model A is a purely additive model. Model $\mathrm{C}$ allows for the dam's environmental effect.

heritability dropped from 0.57 to 0.42 in model A and model B, and dropped from 0.65 to 0.31 in model C. Model A and model B yielded very similar estimates. The estimates obtained with model A and model B were generally higher than those obtained with model $\mathrm{C}$, the difference represented $10 \%$ for the G0-G4 data set, and 27\% for the G0-G16 data set (Tab. II).

Table III shows estimates from the analyses of the partial data sets omitting records from earlier generations, including or excluding pedigree information back to generation 0 . The heritability of the base population defined by generation 0 decreased when considering only the data of later generations, from 0.49 to 0.20 in line L1 and from 0.43 to 0.19 in line L2, by contrast, it remained almost a constant in the control line, 0.56-0.57. In the analyses ignoring back pedigree information, the reduction of genetic variance along selection was obvious, when, for instance, the heritability values estimated in G4, G8 and G12 were 0.37, 0.28 and 0.17 in line L1.

\subsection{Genetic gain}

The linear regression of the deviations from the control line on the phenotypic scale showed a yearly increase in average clutch length of $0.65 \pm 0.08\left(\mathrm{R}^{2}=\right.$ $0.82)$ and $0.65 \pm 0.06\left(R^{2}=0.90\right)$ for the normally feathered line (L1) and the naked neck line (L2), respectively. The results of BLUP evaluation, using a heritability of 0.42 , may be compared with the genetic trends estimated by deviation from the control line, only after Box-Cox transformation of the average clutch length (Fig. 3). On the transformed scale, the linear regression of 
Table III. Effect of omitting either (1) performance data or (2) pedigree and performance data from earlier generations, on heritability estimates (line L1, L2 with Model A, control line with Model B), and on realized heritability (lines L1 and L2 only).

\begin{tabular}{|c|c|c|c|c|c|c|c|}
\hline \multirow{2}{*}{\multicolumn{2}{|c|}{$\begin{array}{l}\text { Data set } \\
\text { Generations }\end{array}$}} & \multirow{2}{*}{$\begin{array}{c}\text { Base } \\
\text { Population }\end{array}$} & \multicolumn{2}{|l|}{ Line L1 } & \multicolumn{2}{|l|}{ Line L2 } & \multirow{2}{*}{$\begin{array}{c}\text { Control line } \\
h^{2} \pm \mathrm{SE} \\
\end{array}$} \\
\hline & & & $h^{2} \pm \mathrm{SE}$ & $h_{r}^{2}$ & $h^{2} \pm \mathrm{SE}$ & $h_{r}^{2}$ & \\
\hline \multirow[t]{3}{*}{ (1) } & G16-G5 & G0 & $0.49 \pm 0.056$ & - & $0.43 \pm 0.039$ & - & $0.56 \pm 0.040$ \\
\hline & G16-G9 & G0 & $0.42 \pm 0.034$ & - & $0.37 \pm 0.045$ & - & $0.57 \pm 0.042$ \\
\hline & G16-G13 & G0 & $0.20 \pm 0.045$ & - & $0.19 \pm 0.046$ & - & $0.57 \pm$ \\
\hline \multirow[t]{3}{*}{ (2) } & G5-G8 & G4 & $0.37 \pm 0.033$ & 0.18 & $0.34 \pm 0.027$ & 0.22 & $0.55 \pm 0.026$ \\
\hline & G9-G12 & G8 & $0.28 \pm 0.027$ & 0.19 & $0.31 \pm 0.065$ & 0 & $0.55 \pm 0.035$ \\
\hline & G13-G16 & G12 & $0.17 \pm 0.042$ & 0.18 & $0.16 \pm 0.044$ & 0.14 & $0.51 \pm 0.050$ \\
\hline
\end{tabular}

L1 line: selected and normally feathered; L2 line: selected and naked neck; control line: unselected and segregating for the naked neck gene.

\section{Genetic gain}

(Transformed value)

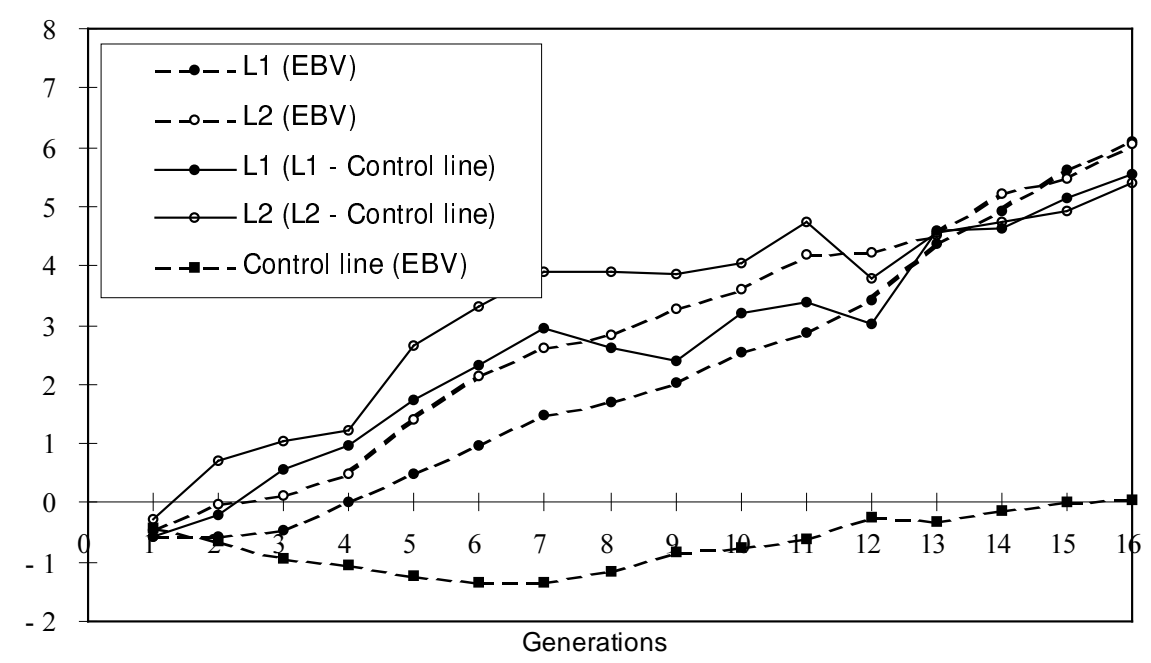

Figure 3. The genetic gains in classic and animal model methodology for transformed clutch length.

genetic gains estimated by the deviations from the control line was $0.37 \pm 0.02$ $\left(R^{2}=0.94\right)$ and $0.33 \pm 0.04\left(R^{2}=0.85\right)$ for lines $L 1$ and $L 2$, respectively. The estimated breeding values with the animal model followed a yearly increase of $0.46 \pm 0.02\left(\mathrm{R}^{2}=0.98\right)$ and $0.43 \pm 0.01\left(\mathrm{R}^{2}=0.98\right)$, for lines $\mathrm{L} 1$ and $\mathrm{L} 2$, respectively, which represented a yearly gain of about $30 \%$ of the genetic standard deviation. 
The selection response estimated from the classical method was more fluctuating than the response obtained from the mixed model methodology. The least-squares estimator used only the records from one generation at a time, whereas, the mixed model methodology used information from more generations. Consequently, the curve of the genetic trend was smoother when averaging EBV, as found by Pinard et al. [30] and Meyer [25].

\subsection{Realized heritability}

The cumulated selection differential and intensity of selection are given in Table IV. The selection differentials for the normally feathered line (L1) were constantly lower than that of the naked neck line (L2), and the average selection differentials per generation in lines L1 and L2 were 1.44 and 1.74 on the transformed scale, respectively. The cumulative selection response (CSR) for line L2 increased faster than for line L1 until generation 11, by contrast, the CSR for line L1 increased faster than for line L2 after generation 11 and was even larger than for line L2 at the last generation. Consequently the realized heritability was higher in line $\mathrm{L} 1$, being 0.28 , than in line $\mathrm{L} 2$, being 0.22 . When calculated over the periods G5-G8, G9-G12, and G13-G16, the realized heritability appeared rather constant in line L1, but fluctuated more in line L2 (Tab. III).

\section{DISCUSSION}

\subsection{Data distribution and transformation}

The distribution of clutch length was nearly a Poisson distribution. Ayorinde and Olagbuyiro [2] also reported that clutch size varied from 1 to 12 eggs, and the highest frequency was $72.3 \%$ for a $1-3$ egg clutch. The Box-Cox transformation of egg production traits resulted in increases in estimated heritability, which were reported by Ibe and Hill [20], Besbes et al. [7] and Chapuis et al. [13]. In the present study, the estimated heritability values were $0.15 \pm 0.01$ and $0.42 \pm 0.02$ for un-transformed and transformed variables, respectively. However, the data distributions over generations were dynamic, so that the skewness and kurtosis changed along generations as a result of selection. Figure 4 shows the distribution of clutch length for the two selected lines in three periods, each of them representing five generations. The skewness and kurtosis were increasing in last generations because of the occurrence of hens showing extremely high values. The optimal transformation parameter t, to fulfill the same normality condition, was not a constant over time. Nevertheless, Banks et al. [3] reported that REML is robust and they verified this robustness even for slight skewness. Therefore, in the present analysis, in order to avoid the scale diversity due to different transformation parameters, we used the same 
Table IV. Intensity of selection (i), cumulative selection responses (CSR), cumulative selection differentials (CSD), and realized heritability for transformed clutch length per generation.

\begin{tabular}{|c|c|c|c|c|c|c|c|c|c|c|}
\hline \multirow{2}{*}{$\begin{array}{l}\text { Generation, } \\
\mathrm{n}\end{array}$} & \multicolumn{5}{|c|}{ Line L1 } & \multicolumn{5}{|c|}{ Line L2 } \\
\hline & $\mathrm{i} /$ sire & $\mathrm{i} / \mathrm{dam}$ & CSR & CSD & $h_{r}^{2}$ & i/sire & $\mathrm{i} / \mathrm{dam}$ & CSR & CSD & $h_{r}^{2}$ \\
\hline 1 & 0.65 & 1.03 & - & 0.85 & - & 0.16 & 0.89 & - & 1.01 & - \\
\hline 2 & 1.27 & 1.02 & 0.43 & 0.87 & - & 1.29 & 1.02 & 1.01 & 1.37 & - \\
\hline 3 & 1.31 & 1.12 & 1.18 & 2.11 & 0.78 & 1.37 & 1.12 & 1.41 & 2.70 & 0.57 \\
\hline 4 & 1.26 & 1.16 & 1.65 & 3.76 & 0.63 & 1.32 & 1.23 & 1.54 & 4.81 & 0.63 \\
\hline 5 & 1.32 & 1.20 & 2.36 & 5.42 & 0.54 & 1.31 & 1.24 & 3.02 & 6.96 & 0.54 \\
\hline 6 & 1.23 & 1.17 & 2.93 & 7.37 & 0.48 & 1.17 & 1.17 & 3.75 & 8.84 & 0.47 \\
\hline 7 & 1.28 & 1.12 & 3.53 & 8.55 & 0.38 & 1.20 & 1.02 & 4.18 & 10.48 & 0.40 \\
\hline 8 & 1.23 & 1.05 & 3.22 & 10.13 & 0.31 & 1.06 & 0.79 & 4.24 & 11.77 & 0.36 \\
\hline 9 & 1.30 & 1.31 & 3.09 & 11.65 & 0.33 & 1.27 & 1.15 & 4.18 & 13.44 & 0.33 \\
\hline 10 & 1.22 & 1.17 & 3.87 & 13.10 & 0.30 & 1.18 & 1.22 & 4.43 & 15.40 & 0.33 \\
\hline 11 & 1.19 & 1.00 & 3.99 & 14.80 & 0.25 & 1.27 & 1.25 & 5.07 & 17.46 & 0.24 \\
\hline 12 & 1.48 & 1.20 & 3.64 & 16.45 & 0.32 & 1.36 & 1.30 & 4.11 & 20.13 & 0.24 \\
\hline 13 & 1.29 & 1.28 & 5.22 & 18.20 & 0.29 & 1.14 & 1.20 & 4.90 & 22.37 & 0.23 \\
\hline 14 & 1.27 & 1.37 & 5.20 & 19.92 & 0.29 & 1.12 & 1.27 & 5.08 & 23.92 & 0.22 \\
\hline 15 & 1.38 & 1.19 & 5.83 & 21.65 & 0.28 & 1.27 & 1.29 & 5.26 & 26.04 & 0.22 \\
\hline 16 & 1.03 & 0.86 & 6.15 & - & - & 0.89 & 0.89 & 5.72 & - & - \\
\hline
\end{tabular}

L1 line: selected and normally feathered; L2 line: selected and naked neck. $h^{2}=\frac{\mathrm{CSR}_{n+1}}{\mathrm{CSD}_{n}}$.

parameter for all the analyses, and checked that normality was satisfied for the base population.

The distribution of average clutch length may depart from normality for different reasons. First, lower values are truncated towards 1 , whereas there is no limit for high values. As a physiological consequence, indeed, clutch length tends towards infinity when the time interval between the ovipositions tends towards $24 \mathrm{~h}$. Second, the observed distribution might contain a mixture of distributions due to the possible segregation of an unknown mutation, picked up by selection. Tixier-Boichard et al. [40] found a mixture of two non-normal distributions in line L2 at the 10th generation, one of which consisted in 4\% of the animals, with a mean value at three standard deviations above the mean of the main distribution. In the future, it would be necessary to analyze the 

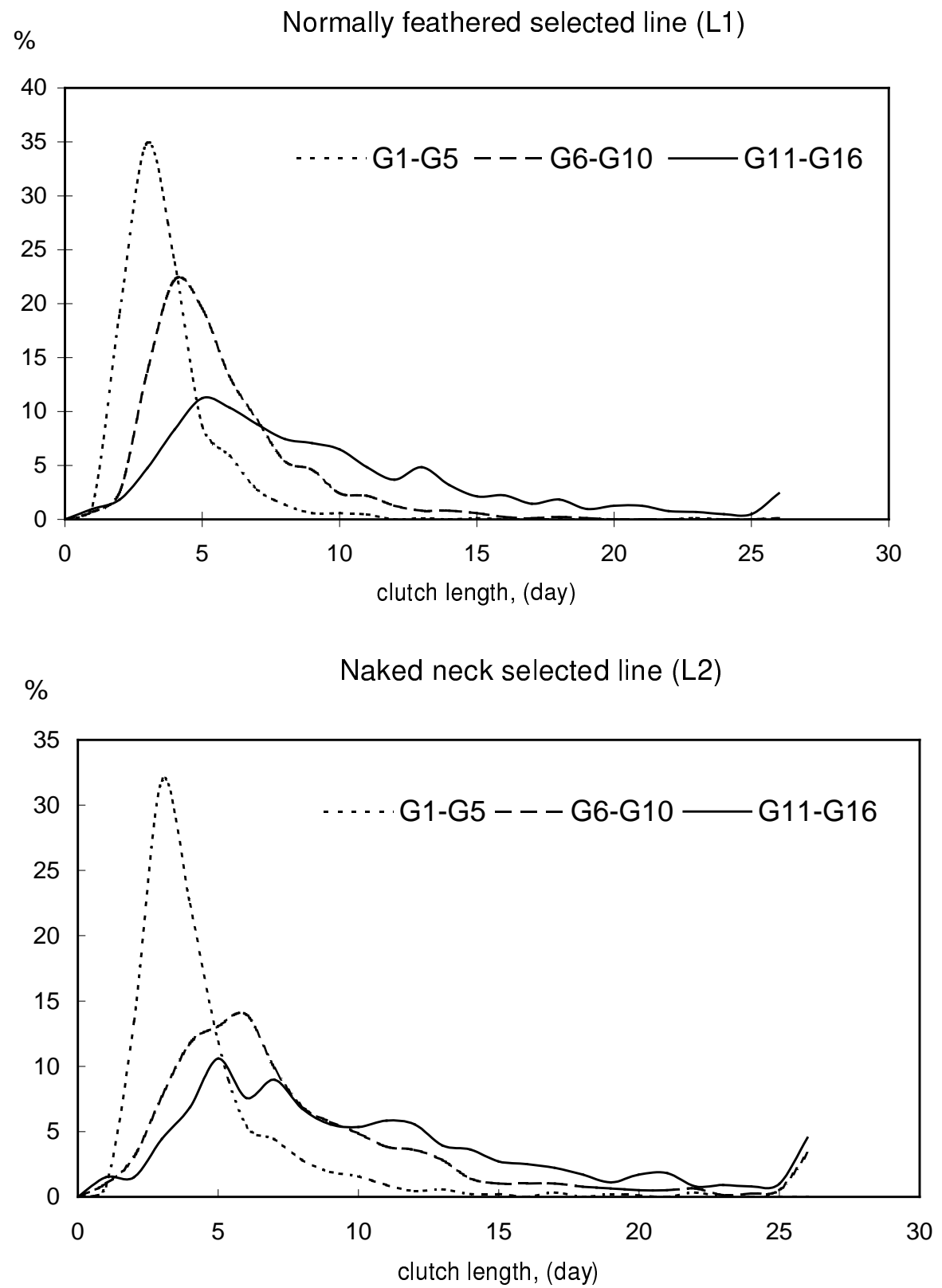

Figure 4. The clutch length distribution (\%) for two selected lines over three periods of five generations each.

heterogeneity of sire family variances in order to test the hypothesis of a major gene affecting clutch length. 


\subsection{Phenotypic trends, selection response, and the effect of the $N A$ gene}

Selection for average clutch length in the dwarf laying hens achieved significant progress. At generation 16, the average clutch length was 15.16, 14.87 and 3.63 for the normally feathered line (L1), the naked neck line (L2) and control line (C), respectively. The two selected lines showed a similar selection response in the last generations. We suggest that the selected lines have reached an optimum performance level from the viewpoint of the oviposition pattern. In a previous study [38], at generation 1, 5 and 10, the time of lay was recorded manually on an hourly basis, and the results showed a significant reduction of the interval between the ovipositions from $27 \mathrm{~h}$ to $24.5 \mathrm{~h}$. At the 16 th generation, the time interval between the ovipositions was $24.7,24.3$ and $26.8 \mathrm{~h}$ in lines L1, L2 and the control, respectively (unpublished data). The decrease in the time interval between the ovipositions approached the $24 \mathrm{~h}$ limit fixed by the lightdark cycle. In another experiment [44], oviposition times were recorded under a normal light-dark cycle for a commercial White Leghorn strain. The distribution statistics of oviposition intervals clearly showed the physiological barrier in egg production imposed by a $24 \mathrm{~h}$-cycle. Mean oviposition intervals ranged from 24.1 to 26.3. In the same $24 \mathrm{~h}$ light-dark cycle condition, McClung [23] selected single comb White Leghorns for a shorter intra-clutch interval between ovipositions: the average time interval between the ovipositions significantly decreased from 25.6 to $24.38 \mathrm{~h}$ after seven generations, and the clutch length increased significantly from 5.1 to 12.8 days, but at the last two generations the average clutch length remained the same, 12.8 days. The selection would be expected to become less effective with increasing generations, unless the lightdark cycle is changed. Lillpers and Wilhelmson [21] compared three selected lines, and suggested the oviposition pattern was a good criterion for improved egg production, because of the higher heritability and genetic correlation with egg production. In the present work, clutch length was inversely related to the interval between the ovipositions, and its measurement was easier than monitoring the oviposition time everyday, although it may have been influenced by false recording due to atypical very short sequences and internal ovulations.

During the course of selection, a higher selection response for line L2 took place in the first generations, whereas inversely, a higher selection response took place in the last generations for line L1. This difference could be due either to an effect of random drift, or to a change in selection intensity, or to an effect of the $N A$ gene, or to a genotype $\times$ environment interaction. TixierBoichard et al. [40] compared the selection response achieved in L1 and L2 lines at generation 10, taking into account an approximate drift variance, and the result showed a significant difference in genetic trends between the lines. The negative effect associated with the non naked neck genotype within the control line could suggest that L1 started with an initial "handicap". After pooling the 
data of G6, G8 and G10 to G16 of the control line, the analysis showed a positive effect of the $N A$ gene on the mean and on the coefficient of variation of the clutch length with 3.09, 3.28, 3.34 and $35.0 \%, 41.2 \%, 42.8 \%$, for $N A^{*} N / N A^{*} N$, $N A * N A / N A * N$ and $N A^{*} N A / N A * N A$ genotypes, respectively. On the contrary, the $N A$ gene did not significantly affect the clutch length according to the PEST analysis, which was performed on the transformed value of the clutch length. This suggests that the main effect of the $N A$ gene on clutch length would be an increased variability due to an increased proportion of animals with extreme values. This effect disappeared after normalization of the distribution of clutch length. Indeed, phenotypic variability was larger in line L2 and higher selection differentials could be achieved. However, a higher selection intensity was observed in males in L1 as compared to L2, starting from G12 (Tab. II). Furthermore, a genotype $\times$ environment interaction, took place in the selection history of lines L1 and L2, when a difference was found between the two selected lines regarding the ALV infection, with a higher incidence in line L1 between G4 and G7. ALV infection is known to decrease egg production [15]. The difference in ALV infection between the L1 and L2 lines could not be explained by a direct effect of the NA gene on susceptibility to leucosis, because no difference was found between the genotypes at the NA locus within the control line, following a challenge with the Rous sarcoma virus [36]. It was concluded that the higher incidence of ALV infection in line L1 was a random phenomenon.

\subsection{Inbreeding level}

Although inbreeding tended to reduce the average clutch length, the inbreeding coefficient increased slowly in the selected lines. The rate of inbreeding and its effect on average clutch length did not introduce a significant difference between the two selected lines. In a study of inbreeding depression on production traits of White Leghorns [34], inbreeding tended to reduce egg number and delayed the age at first egg in all lines, but in a line selected on egg weight out of three, a significant effect of inbreeding was also found on fertility and hatchability.

\subsection{Genetic parameters: REML estimates and realized heritability}

Estimated heritability of clutch length was reported only in a few studies. The estimated values ranged from $0.19 \pm 0.11$ to $0.87 \pm 0.39$ [22] and $0.15 \pm 0.05$ to $0.34 \pm 0.07$ [4] and were obtained from the analysis of untransformed data.

Assuming an infinitesimal model [12], REML estimation of genetic variance will account for the effects of selection on estimated parameters, such as genetic drift, inbreeding and gametic disequilibrium. In the present work, all the information was included, but the estimated heritabilities tended to decrease during the course of the experiment (Tab. II), suggesting that the infinitesimal 
model may not be appropriate. An explanation could be that changes of gene frequencies may have occurred, and that the number of loci affecting clutch length may be limited, with the possible segregation of a few genes with large effects. Previous analyses of other selection experiments using mixed model methodology $[25,30]$ also observed changes in estimated heritability, suggesting departure from the infinitesimal model assumption of unlinked additive genes each of very small effect. Furthermore an analysis omitting data from earlier generations and ignoring earlier pedigree information is expected to give an estimate of the genetic variance in different generations. As expected, the heritabilities were decreasing along selection, and genetic variance also decreased slightly.

With the different models used to estimate genetic variance, the estimated heritability values were nearly the same for either model A or model B. This suggested that the genotype at the NA locus could be neglected in this analysis. Model $\mathrm{C}$ was aimed at estimating the influence of maternal and/or dominance effects. Significant common environmental variance was observed only from the 4 th to 8 th generations, with a small value. This suggests that common environmental variance had a small effect in this analysis.

The realized heritability decreased over generations (Tab. IV), particularly, the $h_{r}^{2}$ values were constantly lower than the REML estimate after the 6th generation $\left(h_{r}^{2}<0.42\right)$. One of the reasons, the same as above, was the occurrence of gametic disequilibrium due to a change of genetic variance with the gene frequencies changing in response to selection. Realized heritability underestimated the heritability in the base population as described by Falconer and Mackay [14]. Yet, the realized heritability calculated over the last period, G13-G16, was very similar to the REML estimate obtained for the same period when considering G12 as the base population, both for lines L1 and L2.

\section{CONCLUSION}

In conclusion, our results indicate that average clutch length is effectively improved by selection in dwarf laying hens. The dwarf laying hens carrying or not the naked neck gene showed a similar selection response in the last generations, but a positive effect of the $N A$ gene was observed within the control line as well as on initial response to selection. Regarding genetic variance, the time trend in REML estimates, starting from G0, suggested a departure from the hypothesis of an infinitestimal model. The results from this study indicate that selection for average clutch length has reduced the genetic variance over the generations. Further investigations will involve the estimation of correlated selection responses on the other egg production traits, which may indicate (un)favorable effects associated with an increased clutch length. 


\section{ACKNOWLEDGEMENTS}

The technical help of the staff of the animal caretakers all along the selection experiment is gratefully acknowledged. The authors are grateful to Mrs. Boitard, a computer engineer for programming the data recording and clutch length computing. We are grateful to Dr. D. Boichard and Dr. E. Groeneveld for helpful advice in using VCE, PEST and PEDIG softwares. C.F. Chen was supported by a Ph.D. scholarship from Inra.

\section{REFERENCES}

[1] Amin-Bakhche M., Mérat P., Study of a sex linked dwarfing gene in the fowl: oviposition and characteristics of the successive eggs in laying sequences, Ann. Génét. Sél. Anim. 7 (1975) 13-22.

[2] Ayorinde K.L., Olagbuyiro B., The influence of clutch size and oviposition time on egg weight and egg index in Hubbard layers, Bull. Anim. Health Prod. Afr. 39 (1991) 251-253 (abstract).

[3] Banks B.D., Mao I.L., Walter J.P., Robustness of the restricted maximum likelihood estimator derived under normality as applied to data with skewed distributions, J. Dairy Sci. 68 (1985) 1785-1792.

[4] Bednarczyk M., Kieclzewski K., Szwaczkowski T., Genetic parameters of the traditional selection traits and some clutch traits in a commercial line of laying hens, Arch. Geflügelkd. 64 (2000) 129-133.

[5] Beniwall B.K., Hastings I.M., Thompson R., Hill W.G., Estimation of changes in genetic parameters in selected lines of mice using REML with an animal model. 1. Lean mass, Heredity 69 (1992) 352-360.

[6] Bernier P.E., Arscott G.H., Fifteen years of observations on the dwarf gene in the domestic fowl, Ann. Génét. Sél. Anim. 4 (1972) 183-215.

[7] Besbes B., Ducrocq V., Foulley J.L., Protais M., Tavernier A., Tixier-Boichard M., Beaumont C., Estimation of genetic parameters of egg production traits of laying hens by restricted maximum likelihood applied to a multiple-trait reduced animal model, Genet. Sel. Evol. 24 (1992) 539-552.

[8] Besbes B., Ducrocq V., Foulley J.L., Protais M., Tavernier A., Tixier-Boichard M., Beaumont C., Box-Cox transformation of egg-production traits of laying hens to improve genetic parameter estimation and breeding evaluation, Livest. Prod. Sci. 33 (1993) 313-326.

[9] Boichard D., PEDIG: a fortran package for pedigree analysis suited for large populations, in: Proc. 7th World Congr. Genet. Appl. Livest. Prod., Montpellier, France, 19-23 August 2002, Département Génétique Animale, Inra, CastanetTolosan, CD-ROM communication No. 28-13.

[10] Bordas A., Mérat P., Effect of the naked neck gene on traits associated with egg laying in a dwarf stock at two temperatures, Br. Poult. Sci. 25 (1984) 195-207.

[11] Box G.E.P., Cox D.R., An analysis of transformations, J. Royal Stat. Soc., Series B 26 (1964) 211-243.

[12] Bulmer M.G., The Mathematical Theory of Quantitative Genetics, Oxford, Clarendon Press, 1980. 
[13] Chapuis H., Tixier-Boichard M., Delabrosse Y., Ducrocq V., Multivariate restricted maximum likelihood estimation of genetic parameters for production traits in three selected turkey strains, Genet. Sel. Evol. 28 (1996) 299-317.

[14] Falconer D.S., MacKay T.F.C., Introduction to quantitative genetics, 4th edn., Longman Group Ltd, UK, 1996.

[15] Gavora J.S., Spencer J.L., Effects of lymphoid leukosis virus infection on response to selection, 25th British Poultry Breeders Roundtable, Edinburgh, 1983, pp. 17-24.

[16] Groeneveld E., VCE4 User's Manual, version 1.0, Institute of animal husbandry and animal behavior, Neustadt, Germany, 1996.

[17] Groeneveld E., Computation of random and fixed effects in animal breeding with the PEST package. EAAP satellite symposium, Ph.D. course, University of Debrecen, Faculty of Agronomy, 30 August-5 September, 2001.

[18] Hill W.G., Estimation on realized heritabilities from selection experiments. II Selection in one direction, Biometrics 28 (1972) 767-780.

[19] Hutt F. B., Sex linked dwarfism in the fowl, J. Hered. 50 (1959) 209-221.

[20] Ibe S.N., Hill W.G., Transformation of poultry egg production data to improve normality, homoscedasticity and linearity of genotypic regression, J. Anim. Breed. Genet. 105 (1988) 231-240.

[21] Lillpers K., Wilhelmson M., Genetic and phenotypic parameters for oviposition pattern traits in three selection lines of laying hens, Br. Poult. Sci. 34 (1993) 297-308.

[22] Luc K.M., Miyoshi S., Suzuki M., Mitsumoto T., Heritability estimates of some clutch traits in the laying hen, Jpn. Poult. Sci. 33 (1996) 23-28.

[23] McClung M.R., Albert B.S., Wang B.S., Jones W.T., Response to selection for time interval between ovipositions in the hen, Poultry Sci. 55 (1976) 160-171.

[24] Mérat P., The sex-linked dwarf gene in the broiler chicken industry, World's Poultry Sci. J. 40 (1984) 10-18.

[25] Meyer K., Hill W.G., Mixed-model analysis of a selection experiment for food intake in mice, Genet. Res. 57 (1991) 71-81.

[26] Meuwissen T.H.E., Luo Z., Computing inbreeding coefficients in large populations, Genet. Sel. Evol. 24 (1992) 305-313.

[27] Morris A.J., Pollott G.E., Comparison of selection based on phenotype, selection index and best linear unbiased prediction using data from a closed broiler line, Br. Poult. Sci. 38 (1997) 249-254.

[28] Ollivier L., On the use of animal models in the analysis of selection experiments, Genet. Sel. Evol. 31 (1999) 135-148.

[29] Perez-Enciso M., Toro M., Classical and mixed model analysis of an index selection experiment for fecundity in Drosophila melanogaster, J. Anim. Sci. 70 (1992) 2673-2681.

[30] Pinard M.H., van Arendonk J.A.M., Nieuwland M.G.B., van der Zijpp A.J., Divergent selection for immune responsiveness in chickens: estimation of realized heritability with animal model, J. Anim. Sci. 70 (1992) 2986-2993.

[31] Quaas R.L., Computing the diagonal elements and inverse of a large numerator relationship matrix, Biometrics 32 (1976) 949-953.

[32] SAS $^{\circledR}$, SAS/STAT User's Guide, Version 6, 4th edn., Vol. 1, SAS ${ }^{\circledR}$ Institute Inc., Cary, NC, USA, 1995. 
[33] $\mathrm{SAS}^{\circledR}$, SAS Procedure Guide, 3rd edn, SAS ${ }^{\circledR}$ Institute Inc., Cary, NC, USA, 1990.

[34] Sewalem A., Johansson K., Wilhelmson M., Lillpers K., Inbreeding and inbreeding depression on reproduction and production traits of White Leghorn lines selected for egg production traits, Br. Poult. Sci. 40 (1999) 203-208.

[35] Sorensen D.A., Kennedy B.W., Estimation of genetic variances from unselected and selected populations, J. Anim. Sci. 59 (1984) 1213-1223.

[36] Tixier-Boichard M., Dambrine G., Durand L., Lasserre F., Mérat P., Avian leukosis virus (ALV) infection in dwarf (dw) brown-egg layers selected for clutch length, with or without the naked neck $(\mathrm{Na})$ gene, in: World's Poultry Congress, Amsterdam, 20-24 September 1992, pp. 532-533.

[37] Tixier-Boichard M., Boichard D., Groeneveld E., Bordas A., Restricted maximum likelihood estimates of genetic parameters of adult male and female Rhode Island Red chickens divergently selected for residual feed consumption, Poultry Sci. 74 (1995) 1245-1252.

[38] Tixier-Boichard M., Balluais J., Boitard M., Oviposition pattern in dwarf lines selected for clutch length, in: 2nd European Poultry Breeders Roundtable, Foulum, 6-8 September 1995, Danish Institute of Animal Science, Tjele, 1996, Report No. 73.

[39] Tixier-Boichard M., Planification et résultats d'une expérience de sélection conduite en générations séparées chez la poule pondeuse, in: Séminaire Planification Expérimentale en Génétique Animale, Saint-Martin de Ré, 2-4 avril 1996, Inra, pp. 135-144.

[40] Tixier-Boichard M., Boitard M., Coquerelle G., Mérat P., Genetic improvement of clutch length in dwarf brown-egg layers: additional selection response with the naked neck gene, in: World's Poultry Congress, New Delhi, India, 2-5 September, Vol. 1, 1996, pp. 453-458.

[41] van der Werf J.H.J., de Boer I.H.M, Estimation of the additive genetic variance when base populations are selected, J. Anim. Sci. 68 (1990) 3124-3132.

[42] Yamada Y., Yokouchi K., Nishida A., Selection index when genetic gains of individual traits are of primary concern, Jpn. J. Genetics 50 (1975) 33-41.

[43] Yoo B.H., Sheldon B.L., Podger R.N., Increase in oviposition interval due to the sex-linked dwarf gene in White Leghorns and Australorps, Br. Poult. Sci. 25 (1984) 119-126.

[44] Yoo B.H., Sheldon B.L., Podger R.N., Analysis of oviposition times and intervals in a wide range of layer flocks under normal and continuous lighting regimes, Br. Poult. Sci. 27 (1986) 267-288.

[45] Yoo B.H., Sheldon B.L., Podger R.N., Genetic parameters for oviposition time and interval in a White Leghorn population of recent commercial origin, Br. Poult. Sci. 29 (1988) 627-637. 